\title{
СТРУКТУРА ЭЛЕКТРОИСКРОВЫХ НАНОКОМПОЗИЦИОННЫХ ПОКРЫТИЙ НА МЕТАЛЛИЧЕСКОЙ МАТРИЦЕ
}

\author{
Е. В. Овчинников ${ }^{1}$, Н. М. Чекан ${ }^{2}$, В. М. Хвисевич ${ }^{3}$, \\ А. И. Веремейчик ${ }^{4}$ В. В. Михайлов ${ }^{5}$, Н. Н. Казак ${ }^{6}$ \\ ${ }^{1}$ Д. т. н., доцент, доцент кафедры логистики и методов управления, учреждения образования \\ «Гродненский государственный университет им. Я. Купаль», Гродно, Беларусь, e-mail: ovchin_1967@mail.ru \\ ${ }^{2}$ К. фриз.-мат. н., заведующий лабораторией наноматериалов и ионно-плазменных процессов, \\ ГНУ «Физико-технический институт НАН Беларуси», Минск, Беларусь, e-mail: pec@bas-net.by \\ ${ }^{3}$ K. m. н., доцент, профеессор кафедры прикладной механики учреждения образования «Брестский государственный \\ технический университет», Брест, Беларусь, e-mail: vmhvisevich@bstu.by \\ ${ }^{4}$ K. физ.-мат. н., доцент, старший научный сотрудник испытательного чентра учреждения образования \\ «Брестский государственный технический университет», Брест, Беларусь, e-mail: vai_mrtm@bstu.by \\ ${ }^{5}$ Д. т. н., ведущий научный сотрудник лаборатории электрофизических и электрохимических методов \\ обработки материалов "Борис Лазаренко”, Институт прикладной фризики Академии наук Молдовы, \\ Кишинев, Молдова, e-mail: valentin.mihailov@gmail.com \\ ${ }^{6}$ Аспирант, Институт прикладной фризики Академии наук Молдовы, \\ Кишинев, Молдова, e-mail: kazaknatalia@mail.ru
}

\begin{abstract}
Реферат
Электроискровое легирование (ЭИЛ) проводящих поверхностей твердых тел является в настоящее время перспективным направлением увеличения эксплуатационных свойств материалов. Формирование покрытий сверхтвердых материалов на субстрате позволяет существенно увеличить твердость, износостойкость, стойкость к воздействию высоких температур и давления. В данной статье исследованы химический состав, структура, физико-механические характеристики, морфология покрытий, сформированных на металлических субстратах. Установлено, что технологические параметры формирования электроискровых покрытий оказывают существенное влияние на морфологию, структуру и физико-механические характеристики модифицированных материалов. Структура защитных слоев существенно зависит от химического состава электродов.
\end{abstract}

Ключевые слова: легирование электроискровое, эксплутационные свойства материала, покрытие, морфология материала, электрод.

\section{THE STRUCTURE OF ELECTROSPARK NANOCOMPOSITE COATINGS ON A METAL MATRIX}

Abstract

Y. V. Auchynnikau, N. M. Chekan, V. M. Khvisevich, A. I. Veremeichik, V. V. Mikhailov, N. N. Kazak

Electrospark alloying (ESA) of conducting surfaces of solids is a promising direction for increasing the operational properties of materials at the present time. The formation of coatings of superhard materials on a substrate can significantly increase the hardness, wear resistance, resistance to high temperatures and pressure. This article investigates the chemical composition, structure, physical and mechanical characteristics, morphology of coatings formed on metal substrates. It was found that the technological parameters of the formation of electrospark coatings have a significant effect on the morphology, structure, and physical and mechanical characteristics of the modified materials. The structure of the protective layers depends significantly on the chemical composition of the electrodes.

Keywords: electrospark alloying, material performance properties, coating, material morphology, electrode.

\section{Введение}

Титановые сплавы обладают разнообразными положительными свойствами, в частности имеют низкую плотность, высокую удельную прочность, хорошую стойкость к коррозионному воздействию, биосовместимость [1]. В связи с этим они нашли широкое применение в аэрокосмической, химической промышленности, металлургии, медицине и атомной промышленности. Однако использование титановых сплавов ограничивают не очень высокие триботехнические характеристики, например высокий коэфффициент трения, склонность к адгезионному износу. Данные причины приводят к раннему выходу из строя изделий из титана в различных парах трения [2]. Применение различных методов повышения ресурса работоспособности путем модификации и обработки титановых сплавов с использованием физического или химического осаждения соединений титана из газовой фазы (PVD, CVD), ионной имплантации, термического оксидирования и магнетронное распыление показало положительные результаты [3]. Однако использование данных технологий модифицирования поверх ности твердых субстратов ограничено для широкого модифицирования титановых материалов или твердых тел, на которые наносятся сплавы. Например, из-за высокой температуры возможна десрормация подложек при проведении процесса азотирования, карбонизации или в результате осаждения титановых покрытий методом CVD. Оборудование для нанесения покрытий на основе TiN методом PVD относительно сложно и является дорогостоящим. Кроме того, его трудно использовать при формировании покрытий на крупногабаритных изделиях и деталях. Покрытие, нанесенное методом магнетронного распыления, является относительно тонким С низким КПД. В связи С этим общей задачей является создание покрытий на основе титана с хорошей адгезионной способностью при минимальном подводе энергии на поверхности твердого тела. ЭИЛ - типичная поверхностная технология модифицирования с высокой плотностью энергии и низким тепловыделением, которая широко применяется для создания модифицированных упрочняющих покрытий [4-5]. Использование импульсного разряда высокой энергии между электродом и металлической подложкой позволяет нанести расплавленные материалы электродов на твердую проводящую поверхность для осуществления последующей сварочной реакции с подложкой.

Электроискровое легирование металлических поверхностей основано на явлении электрической эрозии и переноса материала анода 
(инструмента) на катод (деталь) при протекании импульсных разрядов в газовой среде [5-9]. При электроискровом легировании эродированный материал электрода-анода переносится на электрод-катод а материал катода - на анод, причём, как установлено многочисленными экспериментами, преимущественному разрушению и переносу подвергается материал анода. Важным элементом электроискровой обработки материалов в газовой среде является умение управлять процессом обработки и прогнозировать свойства покрытия: толщину, микро- и макроструктуру, физико-механические свойства (износостойкость, коррозионную стойкость, сопротивление усталости и т. д.) [5-9]. На данном этапе накоплен большой экспериментальный опыт по получению с помощью электроискрового легирования покрытий разного типа. Однако до сих пор обобщающей теории электроискрового легирования, позволяющей прогнозировать свойства покрытий, не создано. Это связано с тем, что математическое описание процесса является исключительно сложным из-за наличия большого количества параметров, действующих разнонаправлено. К таким параметрам относятся материалы катода и анода, состав газовой среды, частота, скважность и амплитуда токов искрового разряда, амплитуда и частота вибрации электрода, появление вторичных фаз на катоде и аноде, величина межэлектродного промежутка и т. д. [9].

Исходя из большого количества проведенных экспериментов по формированию титановых сплавов на твердых поверхностях методом ЭИЛ следует, что технологические режимы формирования покрытий оказывают определяющее влияние на их свойства. Ввиду высоких эксплуатационных характеристик покрытий на основе соединений титана, таких как твердость, защита от процессов трения и коррозии, низкого коэфффициента трения, данные соединения являются перспективными для повышения фуункциональных свойств модифицируемых тел.

Целью исследований является изучение особенностей структуры нанокомпозиционных покрытий на металлической матрице, в том числе процессов структурообразования в аморфных областях нанокомпозитов, методами рентгеноструктурного анализа и растровой электронной микроскопии.

\section{Методика эксперимента}

Объектами исследований являлись композиционные покрытия на основе титана, вольфрама, углерода, кремния и азота. Формирование покрытий осуществляли на установке «Impuls-1A» (производство Института прикладной физики Академии наук Молдовы). Составы электродов для формирования покрытий и режимы их осаждения приведены в таблице 1 .

Таблица 1 - Состав электродов и технологические параметры формирования покрытий ЭИЛ на стальных субстратах

\begin{tabular}{|c|c|c|c|c|}
\hline \multirow{2}{*}{\begin{tabular}{|c|} 
Режим \\
формирования \\
покрытия, Дж \\
\end{tabular}} & \multicolumn{4}{|c|}{ 40X13 (субстрат) } \\
\hline & 1 & 2 & 3 & 4 \\
\hline 0,9 & $\begin{array}{c}\text { Ti+Al+C } \\
\text { (электрод } \\
\text { ВТ1-0, A0, } \\
\text { графритовый } \\
\text { электрод } \\
\text { из ГМЗ) }\end{array}$ & $\begin{array}{c}\text { Ti+Al+N } \\
\text { (электрод } \\
\text { TiN +A0) }\end{array}$ & $\begin{array}{c}\text { Ті+С } \\
\text { (электрод } \\
\text { титановый } \\
\text { ВТ1-0, } \\
\text { графритовый } \\
\text { электрод } \\
\text { из ГМ3) } \\
\end{array}$ & $\begin{array}{c}\text { Ti+Si+C } \\
\text { (электрод } \\
\text { из дисилицида } \\
\text { титана, } \\
\text { графитовый } \\
\text { электрод } \\
\text { из ГМ3) } \\
\end{array}$ \\
\hline
\end{tabular}

Рентгеноструктурный анализ применяли для определения структуры электроискровых покрытий. Рентгенограммы получали на рентгеновском дифрактометре общего назначения марки ДРОН-3.0, используя излучение линии $K_{\alpha}$ от трубки с медным антикатодом, фильтрованное на длине волны $\lambda=1,541 \AA$. Межплоскостное расстояние кристаллографических областей определяли по формуле Вульфа-Брэгга:

$$
2 d \sin \Theta=n \lambda,
$$

где $d$ - межплоскостное расстояние, мкм;

$$
\begin{aligned}
& \lambda \text { - длина волны, мкм; } \\
& \Theta \text { - брэгговский угол рассеяния, } \\
& n \text { - порядок дифракционного максимума, } n=1,2, \ldots \text {. }
\end{aligned}
$$

Средний размер кристаллитов $L$ рассчитывали по формуле Шерpepa:

$$
L=\frac{\lambda}{\Delta} \cos Q,
$$

где $\lambda$ - длина волны рентгеновского излучения, нм;

$\Delta$ - полуширина максимума, рад;

$Q$ - угловое положение максимума, рад;

$L$ - средний размер кристаллитов, нм.

Для более детального изучения структурных изменений в полимерах при введении наполнителей исследовали характер корреляционных функций $W(r)$, связанных с функциями радиального распределения атомной плотности $4 \pi r^{2} \rho(r)$ условием, вытекающим из формулы Цернике-Принса:

$$
\begin{aligned}
& W(r)=4 \pi r^{2} \rho(r)-4 \pi r^{2} \rho_{a v}= \\
& =8 \pi r \int \frac{l_{0}(S)-S f_{k}^{2}(S)}{\sum_{k} f_{k}^{2}(S)} S \sin (2 \pi r S) d S^{\prime}
\end{aligned}
$$

где $I_{0}(S)$ - нормированная интенсивность рассеянного рентгеновского излучения;

$$
f_{k}^{2} \text { - структурный фактор } k \text {-го атома; }
$$

$\rho_{a v}$ - средняя атомная плотность; $r$ - модуль межатомного вектора (радиус координационной сферы).

По рентгенограмме определяли угловое положение рефлекса $2 \theta$, интенсивность рефлекса $I$, отношение $I_{m} / I$, где $I_{m}$ - максимальный рефрлекс на рентгенограмме. Для измерения микротвердости покрытий, сформированных на металлах, использовали микротвердомер HWMMT-X7. Принцип действия прибора основан на изменении линейной величины диагонали отпечатка $c$, полученного от вдавливания алмазной пирамиды в исследуемый материал под определенной нагрузкой. Морфологию покрытий исследовали на растровом электронном микроскопе «MIRA3 TESCAN». Химический состав электроискровых покрытий определяли на приборе рентгеновского флуоресцентного анализа «МАКС-G».

\section{Результаты исследований}

Одним из эффективных методов теоретического описания структурных превращений в электроискровых покрытиях, формируемых на металлических субстратах, является сочетание кластерной модели кристаллизации металлической жидкости [6] и модели возникновения активных зарядовых центров на поверхности кристаллов [7]. Данный подход позволяет более точно описать физико-химические процессы, происходящие в структуре электроискровых покрытий.

Согласно полученным данным основным элементом, содержащимся в составе сформированных покрытий, является титан. Концентрация данного вещества зависит от исходного состава электрода.

Исследования химического состава, структуры и морфологии композиционных покрытий проводили методами рентгеноструктурного анализа, оптической и растровой электронной микроскопии, рентгеновского флуоресцентного анализа. На рисунке 1 представлены типичные спектры вторичного флуоресцентного рентгеновского излучения, полученные на исследуемых композиционных покрытиях.

Исходя из полученных результатов, можно предположить, что наиболее высокими прочностными и адгезионными характеристиками буду обладать составы № 2 и № 3, т. к. в них содержится наибольшая концентрация титана из исследуемых составов покрытий. Остальные химические элементы, представленные на спектрах рентгенофлуоресцентного анализа (РФА), принадлежат подложке, изготовленной из стали 40x13. Можно предположить, что концентрация титана в поверхностных слоях системы «покрытие-подложка» будет составлять около 15 масс. \% по отношению к основному элементу субстрата - железу. 


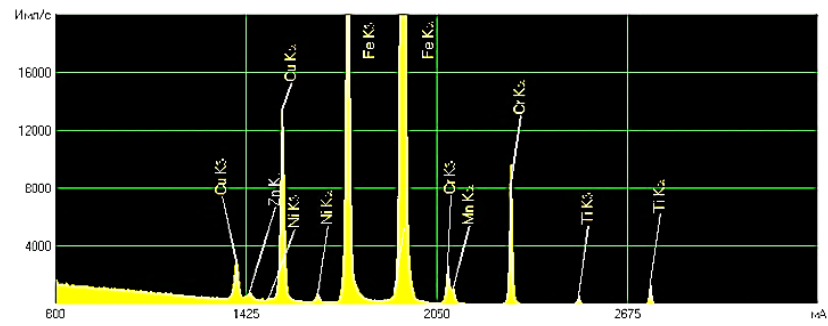

a)

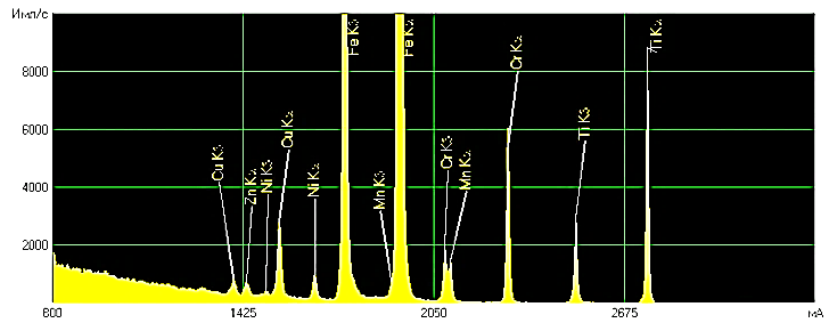

б)

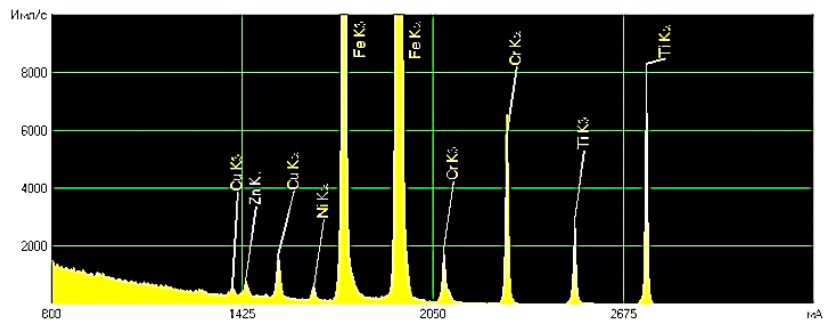

B)
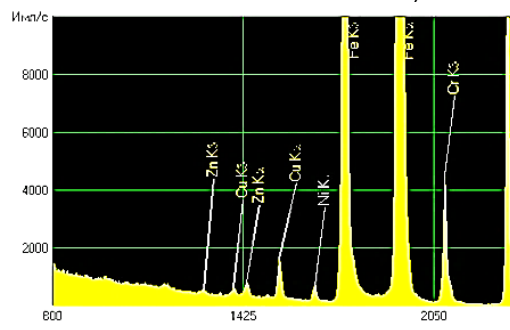

Г)

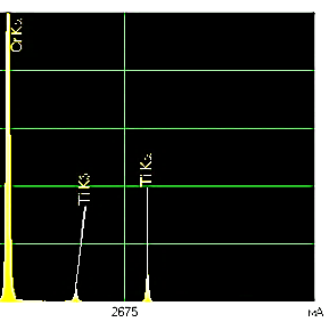

г- состав № 4

а - состав № 1, б - состав № 2, в - состав № 3, г - состав № 4

Рисунок 1 - Спектры электроискровых покрытий покрытий на основе титана, полученные методом рентгеновской флуоресцентного анализа

Проведенные исследования методом рентгеноструктурного анализа покрытий ЭИЛ, сформированных на подложке из стали 40×13 методом электроискрового легирования, представлены на рисунке 2.

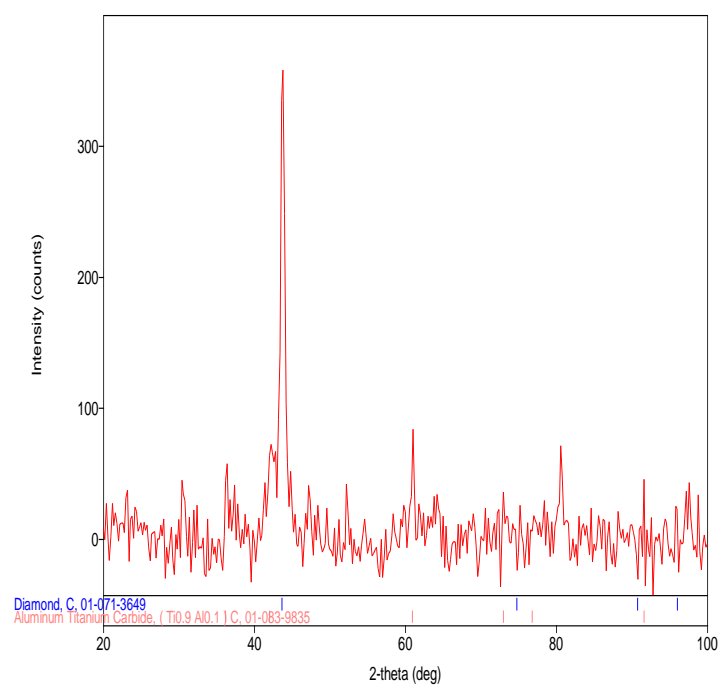

a)

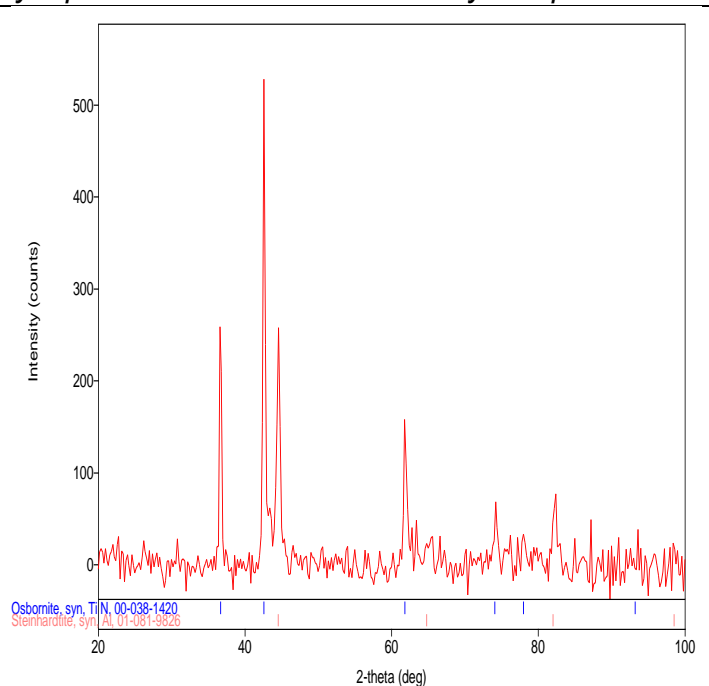

б)

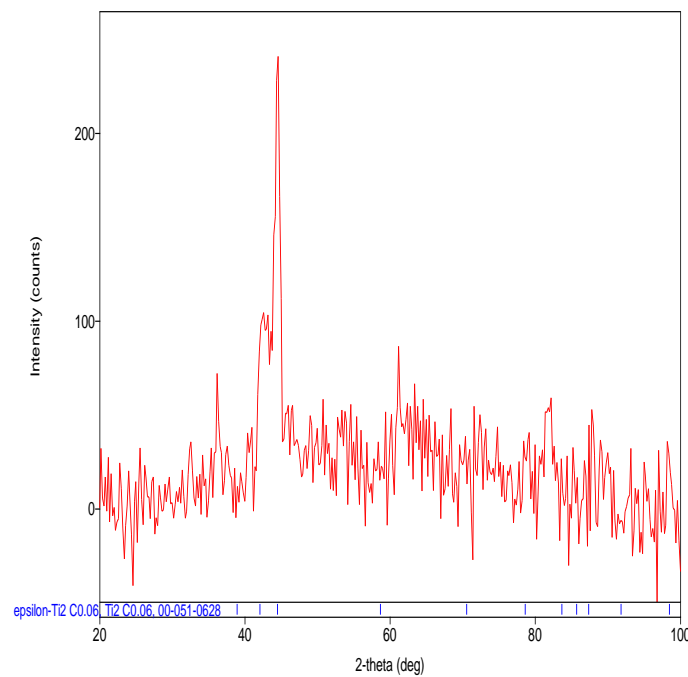

B)

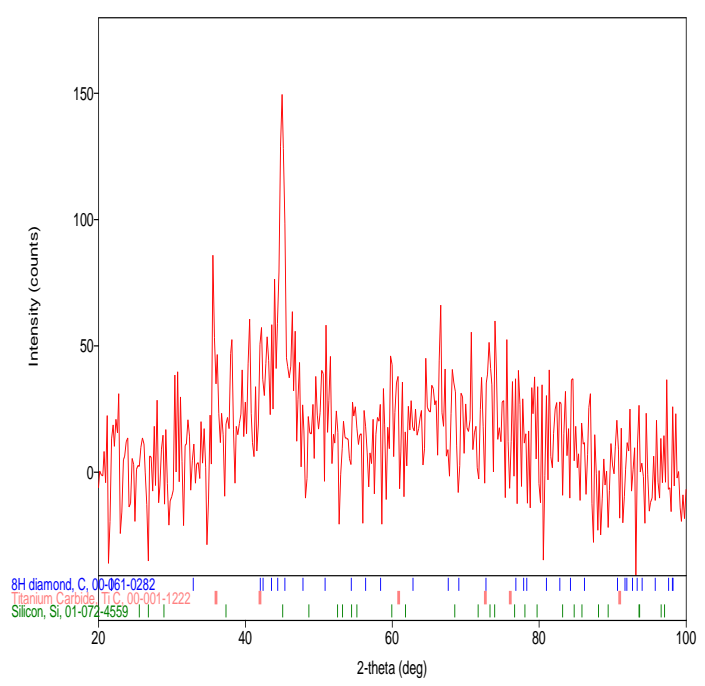

г)

а - состав № 1, б - состав № 2, в - состав № 3, г - состав № 4

Рисунок 2 - Рентгенограммы электроискровых покрытий сформированных на стали 40х13 
Согласно данным рентгеноструктурного анализа исследуемые покрытия, полученные методом электроискрового легирования, представляют собой частично кристаллические образования. Наиболее аморфизированными покрытиями являются составы № 3 и № 4, о чем свидетельсвует достаточно интенсивная модуляция фона на представленных рентгенограммах. Аморфную составляющую покрытия исследовали с применением уравнения Цернике-Принса. Установлено, что структура в аморфной части ЭИЛ покрытий составов № 1 и № 2 обладает большей степени упорядоченности по сравнению с составами покрытий № 3 и № 4. Таким образом можно предположить, что покрытия составов № 1 и № 2 будут обладать более высокими физико-механическими характеристиками.

Исследование морфологии электроискровых покрытий методами растровой электронной и оптической микроскопии показало, что в зависимости от состава электрода формируются отличные по морфологическому строению покрытия (рисунок 3).

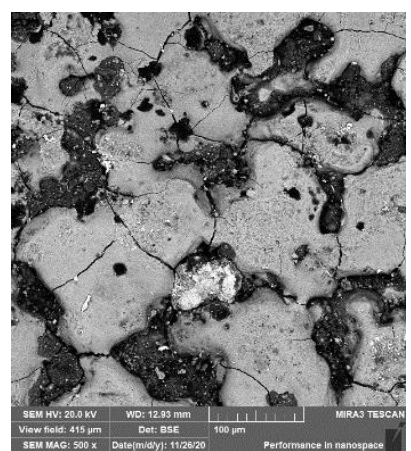

a)

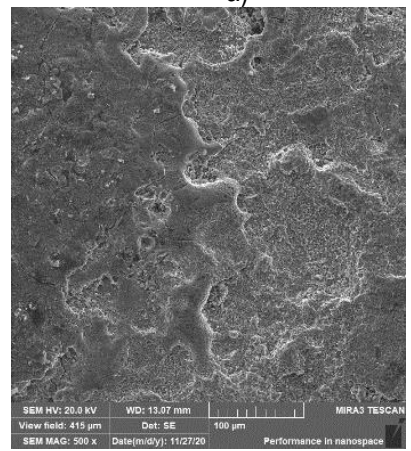

B)

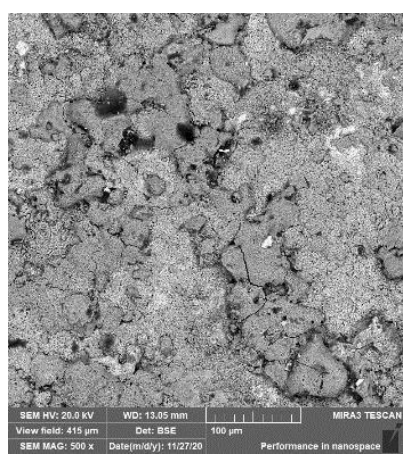

б)

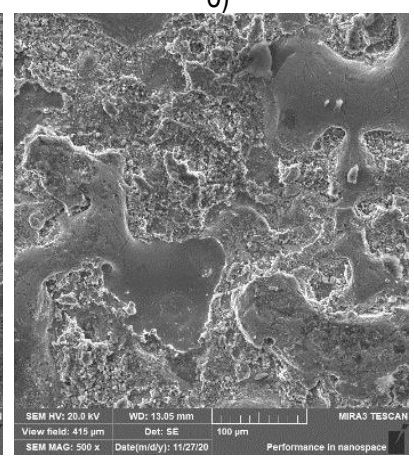

г) а - состав № 1, б - состав № 2, в - состав № 3, г - состав № 4

Рисунок 3 - Мофрология электроискровых покрытий на основе титана при увеличении в 160

При формировании электроискрового покрытия из электрода состава № 1 формируется рельеф по типу «плохого смачивания». Видно, что в покрытии содержится достаточно большое количество дефектов, трещин, проплавление материала покрытия, наблюдается эрозия, нарушения сплошности покрытия. Формирование покрытий из состава электрода № 2 показывает образование мелкодисперсной структуры при одинаковых режимах формирования покрытий. Образование покрытий методом ЭИЛ из электродов № 3 и № 4 приводит к образованию более сплошного покрытия по сравнению с покрытиями № 1 и № 2. Наблюдается уменьшение количество дефектов и трещин в покрытиии. Возможно, что покрытия № 3 и № 4 будут обладать более высокой коррозионной стойкостью по сравнению с покрытиями № 1 и № 2.

Увеличение разрешения при изучении морфологии поверхностных слоев электроискровых покрытий на основе титана показывает формирование фаз, находящихся в области нанометрового диапазона, что может свидетельствовать о получении нанокомпозиционных покрытий методом ЭИЛ (рисунок 4).

Проведенный анализ механических свойств электроискровых слоев, сформированных на стальном субстрате 40х13, подтвердил данные предположения. Микротвердость исследуемых покрытий в 1,8-3,5 раза выше, чем у исходной стальной подложки субстрата.

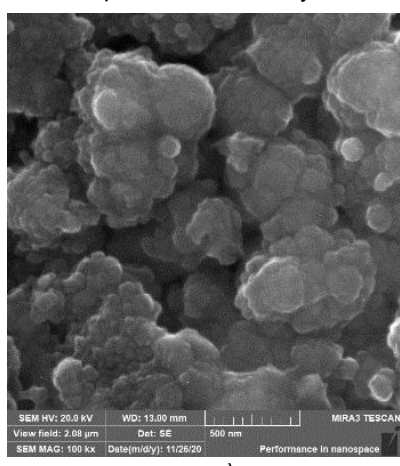

a)

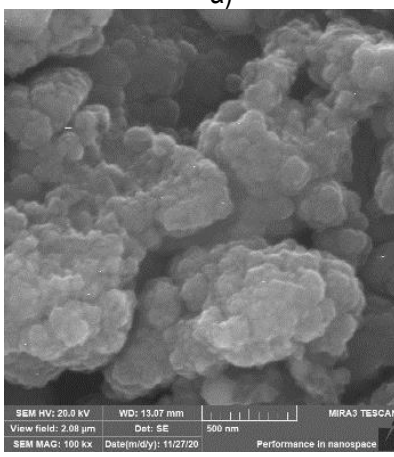

B)

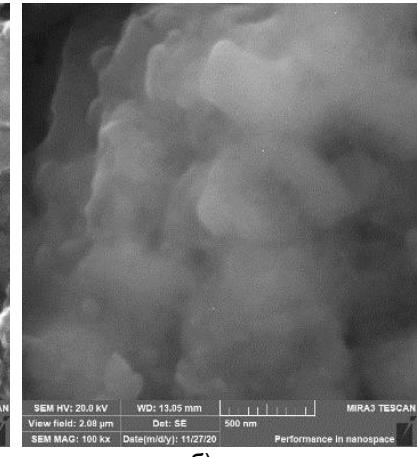

б)

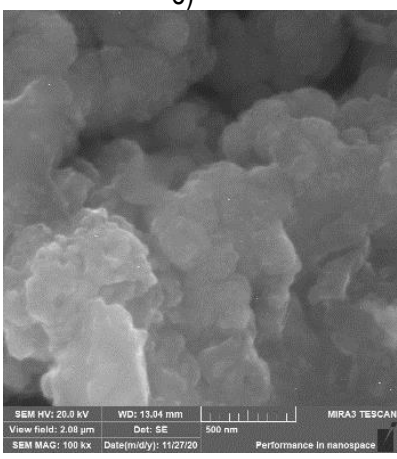

г) а - состав № 1, б - состав № 2, в - состав № 3, г - состав № 4

Рисунок 4 - Мофрология нанокомпозиционных электроискровых покрытий на основе титана при увеличении в 3100

В ходе распыления электрода в электрическом поле происходит формирование аморфно-кристаллического покрытия. Формирование покрытий из графита, Ti, Si, Al, N методом электроискрового легирования при классических режимах осаждения в большинстве случаев приводит к формированию аморфно-кристаллических структур. Аморфно-нанокристаллический сплав, получаемый из данных электродов, представляет собой трехфазный материал, состоящий из металлической аморфной фазы, наноразмерных кристаллов, кристаллической фазы микронного размера. Формируемые покрытия, содержащие аморфные металлические области, у которых отсутствует дальнодействующая трансляционная симметрия и кристаллические дефекты, обладают большим пределом упругой деформации, высокой прочностью, хорошей стойкостью к коррозии и износу. Наличие нанокристаллической фазы в структуре покрытия, различного химического состава также позволяет получить уникальное сочетание улучшенных механических, химических и физических свойств, таких как высокая прочность, уникальные каталитические и термические свойства по отношению к исходному материалу. Содержание в кристаллической структуре покрытий трехкомпонентных соединений также приводит к существенному изменению эксплуатационных характеристик. Таким образом, синергическое взаимодействие трех выше указанных фаз приводит к существенному увеличению физикомеханических характеристик электроискровых покрытий, формируемых из электродов на базе графита, титана, алюминия, кремния.

\section{Заключение}

Нанесение электроискровых покрытий из электродов различного состава приводит к образованию нанокомпозиционных покрытий. Исследуемые покрытия являются частично-кристаллическими. Наличие алюминия в составе покрытия увеличивает степень кристалличности электроискровых покрытий. Введение в состав покрытия кремния увеличивает степень неупорядоченности защитных слоев на основе титана. Согласно данным растровой электронной микроскопии покрытия состава Ті-Al-C являются наиболее дефектными из исследуемого класса покрытий.

Исследования финансировались за счет средств проекта Т1-9МЛДГ-004 
Список цитированных источников

1. Stojadinovic S, Vasilic R, Petkovic M, Kasalica B, Belca I, Zekic A, Zekovic $\mathrm{L}$. Characterization of the plasma electrolytic oxidation of titanium in sodium metasilicate [J]. Applied Surface Science, 2013, 265: 226-233.

2. Durdu S, Aktug S L, Korkmaz K. Characterization and mechanical properties of the duplex coatings produced on steel by electro-spark deposition and micro-arc oxidation [J]. Surface and Coating Technology, 2013, 236: 303-308.

3. Leclair $P$, Berera G P, Moodera J S. Titanium nitride thin films obtained by a modified physical vapor deposition process [J]. Thin Solid Films, 2000, 376(1): 9-15.

4. Структурные особенности нанокомпозиционных покрытий, получаемых методом электроискрового легирования / Е. В. Овчинников [и др.] // Горная механика и машиностроение. - 2020. - № 1. C. $93-100$.

5. Лазаренко, Б. Р. Электроискровая обработка токопроводящих материалов / Б. Р. Лазаренко, Н. И. Лазаренко. - М. : Изд. АН CCCP, 1959. - C.56.

6. Лазаренко, Н. И. О механизме образования покрытий при электроискровом легировании металлических поверхностей / Н. И. Лазаренко // In: Электронная обработка материалов, 1965. № 1. - C.49-53.

7. Parkansky N.Y., Boxman R.I., Goldsmith S. Development and Application of Pulsed-Air Arc Deposition. Surf Coat. Techn. 1993. Vol. 6. Pp. 268-273.

8. Электроискровые технологии восстановления и упрочнения деталей машин и инструментов (теория и практика) / Ф. Х. Бурумкулов [и др.]. Саранск : типография Красный Октябрь, 2003. - 504 с.

9. Технология получения упрочняющих наноструктурированных электроискровых покрытий на алюминиевых сплавах и их использование при восстановлении и ремонте деталей машин [Text tipărit] : Диссертация доктора технических наук (251.03) / Е. В. Юрченко. - Кишинев : [s. n. ], 2016-183 c.

10. Лиопо, В. А. Кристаллизация кластерных жидкостей (статистическая модель) / В. А. Лиопо [и др.] // Прогрессивные технологии и системы машиностроения. - 2015. - № 1. - С. 100-106.

11. Овчинников, Е. В. Возникновение активных заряженных центров на поверхности кристаллов / Е. В. Овчинников, В. А. Лиопо, И. А. Лявшук // Современные проблемы математики и механики : Материалы международной научно-практической конференции профессорско-преподавательского состава и аспирантов; Белгород, 3-7 апреля 2017 г. - Белгород : [Б. и.], 2017. - С. 70-78.

\section{References}

1. Stojadinovic S, Vasilic R, Petkovic M, Kasalica B, Belca I, Zekic A, Zekovic $L$. Characterization of the plasma electrolytic oxidation of titanium in sodium metasilicate [J]. Applied Surface Science, 2013, 265: 226-233.

2. Durdu S, Aktug S L, Korkmaz K. Characterization and mechanical properties of the duplex coatings produced on steel by electro-spark deposition and micro-arc oxidation [J]. Surface and Coating Technology, 2013, 236: 303-308.

3. Leclair P, Berera G P, Moodera J S. Titanium nitride thin films obtained by a modified physical vapor deposition process [J]. Thin Solid Films, 2000, 376(1): 9-15.

4. Strukturnye osobennosti nanokompozicionnyh pokrytij, poluchaemyh metodom elektroiskrovogo legirovaniya / E. V. Ovchinnikov [i dr.] // Gornaya mekhanika i mashinostroenie. - 2020. - № 1. - S. 93-100.

5. Lazarenko, B. R. Elektroiskrovaya obrabotka tokoprovodyashchih materialov / B. R. Lazarenko, N. I. Lazarenko. - M. : Izd. AN SSSR, 1959. S.56.

6. Lazarenko, N. I. O mekhanizme obrazovaniya pokrytij pri elektroiskrovom legirovanii metallicheskih poverhnostej / N. I. Lazarenko // In: Elektronnaya obrabotka materia-lov, 1965. - № 1. - S.49-53.

7. Parkansky N.Y., Boxman R.I., Goldsmith S. Development and Application of Pulsed-Air Arc Deposition. Surf Coat. Techn. 1993. Vol. 6. Pp. 268-273.

8. Elektroiskrovye tekhnologii vosstanovleniya i uprochneniya detalej mashin i instrumentov (teoriya i praktika) / F. H. Bu-rumkulov [i dr.]. - Saransk : tipografiya Krasnyj Oktyabr', 2003. - $504 \mathrm{~s}$.

9. Tekhnologiya polucheniya uprochnyayushchih nanostrukturirovannyh elektroiskrovyh pokrytij na alyuminievyh splavah i ih is-pol'zovanie pri vosstanovlenii i remonte detalej mashin [Text tipărit] : Dissertaciya doktora tekhnicheskih nauk (251.03) / E. V. YUrchenko. - Kishinev : [s. n. ], 2016-183 s.

10. Liopo, V. A. Kristallizaciya klasternyh zhidkostej (statisticheskaya model')/ V. A. Liopo [i dr.] // Progressivnye tekhnologii i sistemy mashinostroeniya.- 2015 .- № 1. - S. 100-106.

11. Ovchinnikov, E. V. Vozniknovenie aktivnyh zaryazhennyh centrov na poverhnosti kristallov / E. V. Ovchinnikov, V. A. Liopo, I. A. Lyavshuk // Sovremennye problemy matematiki i mekhaniki : Materialy mezhdunarodnoj nauchno-prakticheskoj konferencii professorsko-prepodavatel'skogo sostava i aspirantov; Belgorod, 3-7 aprelya 2017 g. - Belgorod : [B. i.], 2017.- S. 70-78.

Материал поступил в редакцию 01.03.2021 